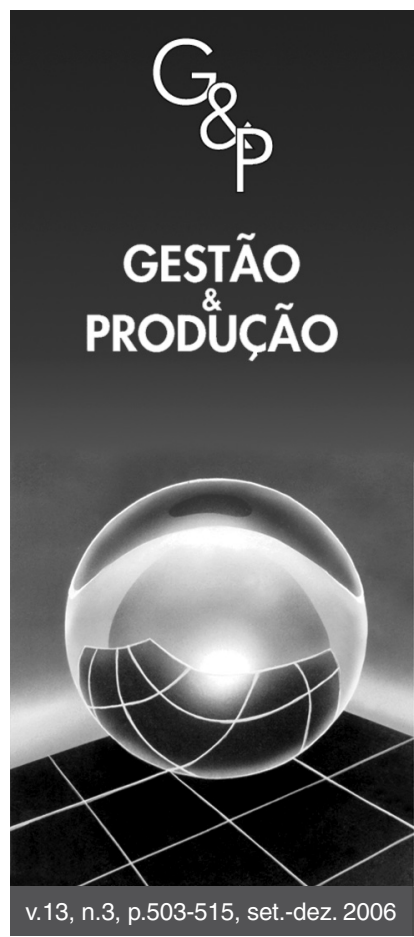

\title{
A GESTÃO AMBIENTAL EM INSTITUIÇÕES DE ENSINO SUPERIOR: MODELO PARA IMPLANTAÇÃO EM CAMPUS UNIVERSITÁRIO
}

\author{
Joel Tauchen \\ Programa de Pós-Graduação em Engenharia - PPGENG, \\ Faculdade de Engenharia e Arquitetura, Universidade de Passo Fundo - UPF, \\ Campus I, Km 171, BR 285, Bairro São José, C. P. 611, CEP 99001-970, \\ Passo Fundo, RS, Brasil, \\ e-mail: tauchenjoel@ cfjl.com.br \\ Luciana Londero Brandli \\ Faculdade de Engenharia e Arquitetura - FEAR, \\ Universidade de Passo Fundo - UPF, Campus I, Km 171, BR 285, \\ Bairro São José, C. P. 611, CEP 99001-970, Passo Fundo, RS, Brasil, \\ e-mail: brandli@upf..br \\ Recebido em 06/7/06 \\ Aceito em 30/11/06
}

Resumo

A preocupação com o desenvolvimento sustentável e ações de gestão ambiental vem ganhando um espaço crescente nas Instituições de Ensino Superior. Isto tem se revelado a partir da abordagem educacional, na preparação de estudantes e fornecimento de informações e conhecimento sobre gestão ambiental e nos exemplos práticos incorporados na operação de seus campi. Este artigo tem o objetivo de propor uma sistematização de procedimentos, culminando num modelo para a implantação de um SGA, adaptado às IES que iniciarão a implantação de um campus universitário, permitindo a essas instituições controlarem os impactos ambientais e se adequarem à legislação, ainda no momento da concepção da sua infra-estrutura. A base da proposta é um levantamento de benchmarkings nacionais $e$ internacionais de boas práticas de sustentabilidade ambiental em campus universitário. O modelo está fundamentado no ciclo PDCA. Os exemplos apresentados indicam ações isoladas em cada universidade, sendo que a maioria destina-se a situações nas quais a instituição já está implementada e funcionando. Esta situação revela a preocupação crescente de adaptação das universidades em busca de um desenvolvimento sustentável, não só no aspecto do ensino, mas também nas de práticas de funcionamento ambientalmente corretas.

Palavras-chave: universidades, campus, gestão ambiental, sustentabilidade.

\section{Introdução}

A gestão ambiental vem ganhando um espaço crescente no meio empresarial. O desenvolvimento da consciência ecológica em diferentes camadas e setores da sociedade mundial acaba por envolver também o setor da educação, a exemplo das Instituições de Ensino Superior (IES).

No entanto, ainda são poucas as práticas observadas nas IES, as quais têm o papel de qualificar e conscientizar os cidadãos formadores de opinião de amanhã.

Na visão de Careto e Vendeirinho (2003), as Universidades e outras Instituições de Ensino Superior precisam praticar aquilo que ensinam. Enquanto as universidades são freqüientemente vistas como instituições estagnadas e burocráticas, outras instituições demonstraram ser ca- pazes de, pelo menos, iniciar o caminho da sustentabilidade.

O papel de destaque assumido pelas IES no processo de desenvolvimento tecnológico, na preparação de estudantes e fornecimento de informações e conhecimento, pode e deve ser utilizado também para construir o desenvolvimento de uma sociedade sustentável e justa. Para que isso aconteça, entretanto, torna-se indispensável que essas organizações comecem a incorporar os princípios e práticas da sustentabilidade, seja para iniciar um processo de conscientização em todos os seus níveis, atingindo professores, funcionários e alunos, seja para tomar decisões fundamentais sobre planejamento, treinamento, operações ou atividades comuns em suas áreas físicas. 
Esse artigo tem o objetivo de apresentar um levantamento de benchmarkings nacionais e internacionais de boas práticas de sustentabilidade ambiental em campus universitário. Com base nos exemplos encontrados, nas normas de gestão ambiental e no ciclo PDCA, propõe-se uma sistematização de procedimentos, culminando num modelo para a implantação de um SGA, adaptado às IES que iniciarão a implantação de um campus universitário, permitindo a essas instituições controlarem os impactos ambientais e se adequarem à legislação, ainda no momento da concepção da sua infra-estrutura.

\section{Revisão da literatura}

\subsection{O Papel das Instituições de Ensino Superior (IES) rumo ao desenvolvimento sustentável}

Existem duas correntes de pensamento principais referentes ao papel das IES no tocante ao desenvolvimento sustentável. A primeira destaca a questão educacional como uma prática fundamental para que as IES, pela formação, possam contribuir na qualificação de seus egressos, futuros tomadores de decisão, para que incluam em suas práticas profissionais a preocupação com as questões ambientais. A segunda corrente destaca a postura de algumas IES na implementação de SGAs em seus campi universitários, como modelos e exemplos práticos de gestão sustentável para a sociedade.

\subsubsection{Educação para o desenvolvimento sustentável}

O crescimento demográfico, o consumo incontrolável dos recursos naturais e a degradação do meio ambiente passaram a exigir ações corretivas de grande envergadura. Segundo Mayor (1998), a educação é a chave do desenvolvimento sustentável e auto-suficiente. A educação deve ser fornecida a todos os membros da sociedade, de tal maneira que cada um se beneficie de chances reais de se instruir ao longo da vida.

A educação ambiental, um dos pilares do desenvolvimento sustentável, contribui para a compreensão fundamental da relação e interação da humanidade com todo o ambiente e fomenta uma ética ambiental pública a respeito do equilíbrio ecológico e da qualidade de vida, despertando nos indivíduos e nos grupos sociais organizados o desejo de participar da construção de sua cidadania (Zitzke, 2002).

Neste sentido, é necessário um projeto político-pedagógico que estimule o aparecimento do homem-cidadão enquanto ator político, para pensar e construir a proposta eco-desenvolvimentista. Ou seja, um cidadão consciente de sua realidade socioambiental mediante a obtenção de vários tipos de conhecimento sobre ela (Zitzke, 2002).
De forma geral, as IES assumem uma responsabilidade essencial na preparação das novas gerações para um futuro viável. Pela reflexão e por seus trabalhos de pesquisa básica, esses estabelecimentos devem não somente advertir, ou mesmo dar o alarme, mas também conceber soluções racionais. Devem tomar a iniciativa e indicar possíveis alternativas, elaborando propostas coerentes para o futuro (Fouto, 2002; Kraemer, 2004).

A exemplo de Kraemer (2004), que tratou disso, Tauchen et al. (2005), enfatizam que o desenvolvimento sustentável procura nas IES um agente especialmente equipado para liderar o caminho. A missão das IES são o ensino e a formação dos tomadores de decisão do futuro - ou dos cidadãos mais capacitados para a tomada de decisão. Essas instituições possuem experiência na investigação interdisciplinar e, por serem promotores do conhecimento, acabam assumindo um papel essencial na construção de um projeto de sustentabilidade.

Isso vem ao encontro de Fouto (2002) que, ao discutir o papel do Ensino Superior no desenvolvimento sustentável, apresenta a visão da Universidade Politécnica da Catalunha, sob a forma de um modelo (Figura 1).

O modelo apresentado por Fouto aponta quatro níveis de intervenção para as IES:

I. Educação dos tomadores de decisão para um futuro sustentável;

II. Investigação de soluções, paradigmas e valores que sirvam uma sociedade sustentável;

III. Operação dos campi universitários como modelos e exemplos práticos de sustentabilidade à escala local; e

IV. Coordenação e comunicação entre os níveis anteriores e entre estes e a sociedade.

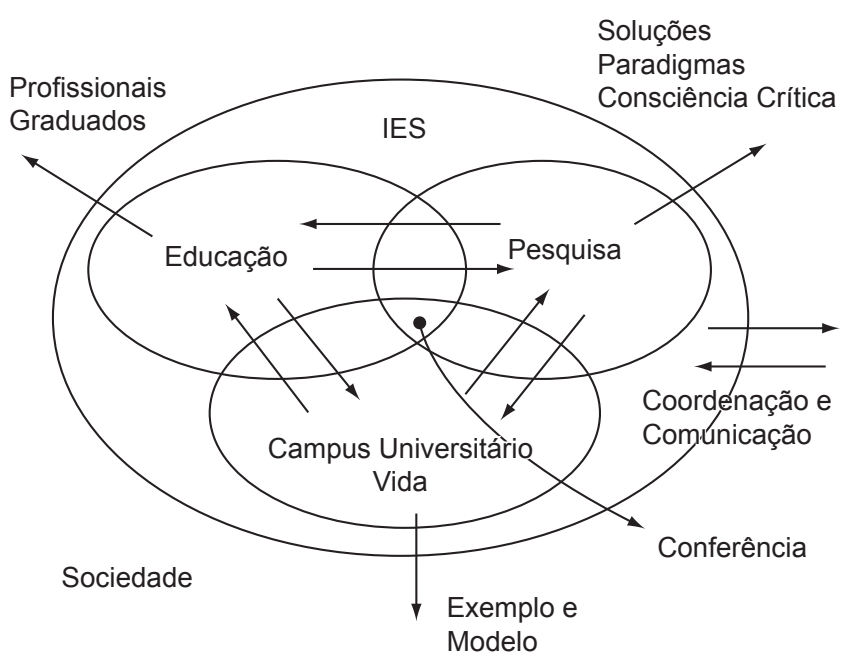

Figura 1. O papel da universidade na sociedade, relativo ao desenvolvimento sustentável. Fonte: Adaptado de Fouto (2002). 
Promover a educação, a consciência pública e reorientar a educação para o Desenvolvimento Sustentável são idéias que constam nos artigos da Rio/92, nos quais se destaca a importância de determinar a integração dos conceitos de ambiente e o desenvolvimento em todos os programas de educação, em particular, a análise das causas dos problemas que lhes estão associados num contexto local, como um objetivo específico (AGENDA 21, 1992).

\subsubsection{Postura e práticas de sustentabilidade nas IES}

Existem razões significativas para implantar um SGA numa Instituição de Ensino Superior, entre elas o fato de que as faculdades e universidades podem ser comparadas com pequenos núcleos urbanos, envolvendo diversas atividades de ensino, pesquisa, extensão e atividades referentes à sua operação por meio de bares, restaurantes, alojamentos, centros de conveniência, entre outras facilidades. Além disto, um campus precisa de infra-estrutura básica, redes de abastecimento de água e energia, redes de saneamento e coleta de águas pluviais e vias de acesso.

Como conseqüência das atividades de operação do campus há geração de resíduos sólidos e efluentes líquidos, consumo de recursos naturais, ou seja, a visão industrial de inputs e outputs. A Figura 2 mostra os principais fluxos de um campus universitário.

Bonett et al. (2002) relatam uma pesquisa efetuada numa universidade localizada na região de Bordeaux - França. Foram identificados os consumos de energia e água, dos serviços disponíveis na instituição. Com relação ao consumo per capita de água, foi constatado que é o mais elevado, se comparado ao consumo médio das grandes cidades. $\mathrm{O}$ fato se agrava em virtude de parte da água consumida no campus ser proveniente de aqüíferos. Quanto ao consumo de energia, os parâmetros permane- ceram semelhantes ao consumo dos habitantes das cidades, o que evidencia a necessidade de controle também desse item.

Na Figura 3, tem-se a representação do sistema de controle das entradas e das saídas da Universidade de Bordeaux, destacando a relação entre o que é consumido, a área do campus, o número de pessoas envolvidas e os resíduos gerados.

Estes aspectos deixam evidente que as IES devem combater os impactos ambientais gerados para servirem de exemplo no cumprimento da legislação, saindo do campo teórico para a prática.

\subsection{Panorama histórico da questão ambiental e as IES}

As IES passaram a introduzir a temática ambiental em seus esquemas de gestão a partir dos anos sessenta. As primeiras experiências surgiram nos Estados Unidos, simultaneamente com as promoções de profissionais nas ciências ambientais, que se estenderam ao longo dos anos setenta. Já nos anos oitenta, o destaque foi para políticas mais específicas à gestão de resíduos e eficiência energética. Durante a década de noventa se desenvolveram políticas ambientais de âmbito global, que congregam todos os âmbitos das instituições, a exemplo do Campus Ecology da University of Wisconsin at Madison ou o Brown is Green, da University of Brown nos Estados Unidos (Delgado e Vélez, 2005).

Até à Conferência do Rio de Janeiro em 1992, as IES praticamente estiveram fora do palco da discussão sobre o desenvolvimento sustentável. A experiência trouxe uma lição clara: as universidades não devem se esquivar ao desafio, pois se não se envolverem, se não usarem as suas forças combinadas para ajudar a resolver os problemas emergentes da sociedade global, então serão ignoradas no despertar de um outro motor de mudança, uma outra agência ou estrutura será convidada a promover a lide-

Fluxos comparáveis de um município de tamanho médio

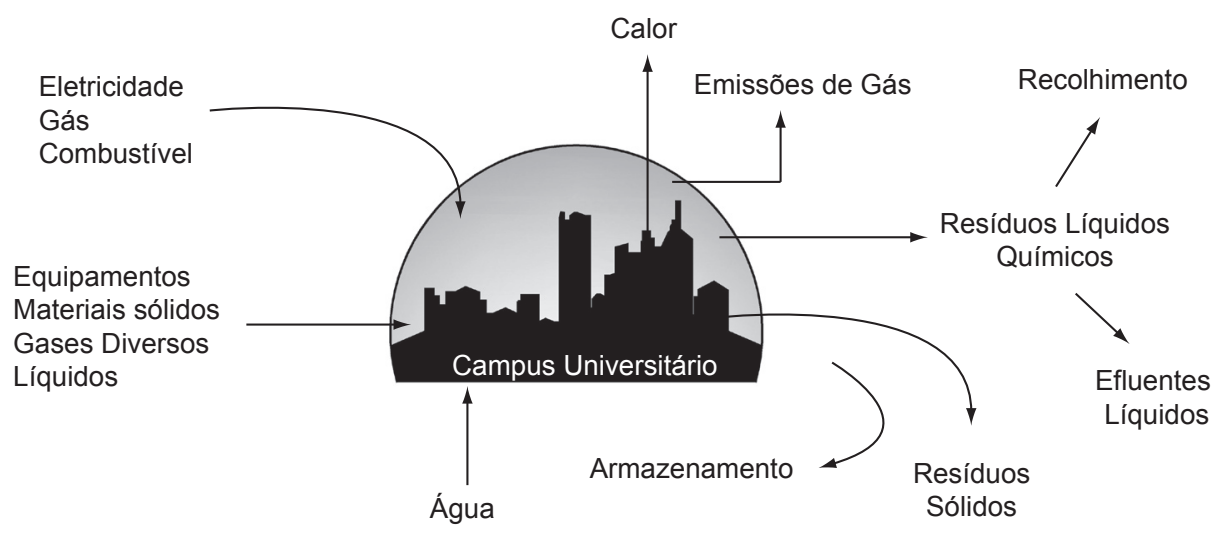

Figura 2. Principais fluxos de um campus universitário. Fonte: Careto e Vendeirinho (2003, p. 9). 


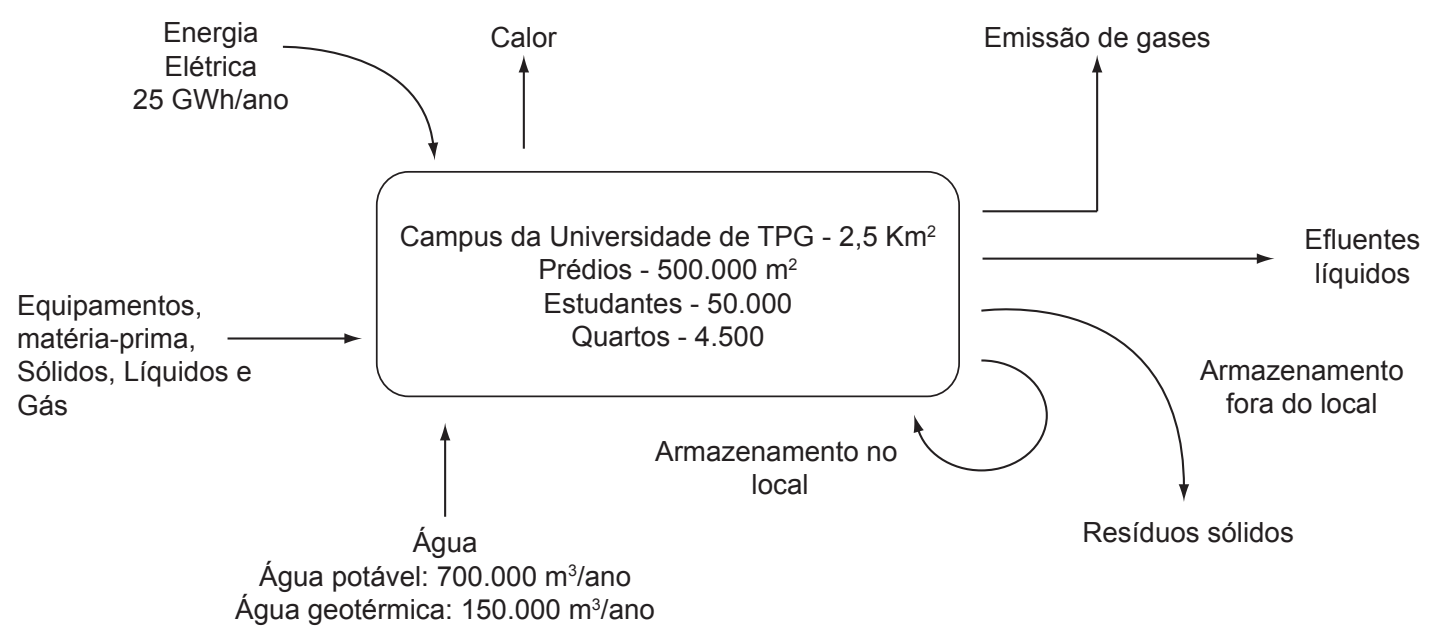

Figura 3. Fluxos de energia e água do campus de Bordeaux. Fonte: Bonnet et al. (2002, p. 15)

rança (INTERNATIONAL ASSOCIATION OF UNIVERSITIES, 1993).

O período entre as Conferências de Estocolmo em 1972 e do Rio de Janeiro em 1992, foi marcado pela emergência de instituições, parcerias e redes de trabalho particularmente empenhadas em (re)conduzir as IES para o lugar que lhe estava reservado (ECOCAMPUS, 1997).

Na Declaração de Talloires, em outubro 1990, reitores e vice-reitores de universidades de várias regiões do mundo tornaram público seu interesse sobre a escala e a velocidade sem precedentes da poluição e da degradação ambiental. Estas mudanças ambientais ameaçam a sobrevivência dos seres humanos, dos milhares de outras espécies vivas, da integridade da terra, da sua biodiversidade, da segurança das nações e das gerações futuras. A declaração de Talloires, como é chamada no campus europeu em Talloires - França -, constatou ser fundamental dirigir ações urgentes a estes problemas para reverter as tendências atuais (THE TALLOIRES DECLARATION, 1990).

Um ano mais tarde, em dezembro de 1991 em Halifax, Canadá, representantes das universidades vinculadas à ONU e da associação das universidades e das faculdades do Canadá uniram-se com representantes das universidades de várias partes do mundo, a exemplo do Brasil, Indonésia e Zimbábue. A declaração de Halifax expressou seu desalento sobre a degradação disseminada e contínua do meio ambiente, das práticas ambientais insustentáveis, além do perverso aumento da pobreza (THE HALIFAX DECLARATION, 1991).

Em agosto 1993, na conclusão da conferência da associação das universidades comunitárias na Suécia, participantes de 400 universidades, de 47 países diferentes, focalizaram o tópico dos povos e do meio ambiente. A questão era encontrar maneiras de as universidades comunitárias, de seus líderes e de os estudantes acoplarem aos seus projetos metodologias para responder ao desafio da sustentabilidade. A reunião na Suécia, inspirada pelos exemplos de Talloires e de Halifax, e decepcionada pela fraca presença das universidades na Agenda 21, adicionou sua voz àquela mundial, que é concernida sobre a degradação do meio ambiente e do aumento da pobreza. Os participantes expressaram que as soluções a estes problemas serão eficazes no momento em que a vulnerabilidade de toda a sociedade for reconhecida e, as energias e as habilidades dos povos em toda parte, forem empregadas numa forma positiva e cooperativa (THE SWANSEA DECLARATION, 1993).

Na Declaração de Kyoto, ocorrida em novembro 1993 no Japão, as IES, em sua reunião, emitiram um chamado a seus 650 membros para que: estabelecessem e disseminassem uma compreensão mais desobstruída do desenvolvimento sustentável; utilizassem recursos das universidades para incentivar uma melhor compreensão por parte dos governos e do público em geral sobre os perigos físicos, biológicos e sociais enfrentados pelo planeta; enfatizassem a obrigação ética da geração atual para superarem as práticas de utilização dos recursos e daquelas disparidades difundidas que se encontram na raiz da insustentabilidade ambiental; realçassem a capacidade das universidades de ensinar e empreender na pesquisa e na ação os princípios sustentáveis do desenvolvimento; e, finalmente, sentissem-se incentivadas a rever suas próprias operações, para refletir quais as melhores práticas sustentáveis do desenvolvimento (THE KYOTO DECLARATION, 1993).

No ano de 1995 foi constituída, em São José na Costa Rica, a Organização Internacional de Universidades pelo Desenvolvimento Sustentável e Meio Ambiente (OIUDSMAE). Esta organização, que atua como uma rede de IES, tem como objetivo o desenvolvimento de programas e de pesquisas no campo do meio ambiente e do desenvolvimento sustentável (OIUDSMA, 2002). 
A Carta Copernicus, instrumento criado por Copernicus, foi um programa interuniversitário de cooperação ao meio ambiente, estabelecido pela associação das universidades européias. A carta expressa um compromisso coletivo em nome de um grande número de universidades. Representa um esforço para mobilizar os recursos das instituições para uma educação elevada a um conceito mais complexo do desenvolvimento sustentável. Os principais objetivos do programa são: incorporar uma perspectiva ambiental em toda a educação universitária e ajudar a desenvolver materiais pedagógicos; estimular e coordenar a integração multidisciplinar de projetos de pesquisa; disseminar amplamente a pesquisa e as descobertas empíricas (COPERNICUS, 1994).

Outro evento importante, ocorrido em março de 2000, foi o encontro de ministros de vários países da região do Mar Báltico no palácio de Haga em Estocolmo, com a finalidade de examinar a praticabilidade da criação de uma rede de ministros, autoridades e instituições educacionais dedicadas à educação para o desenvolvimento sustentável. Em 2002, ocorreu uma segunda reunião na qual participaram a Dinamarca, Estônia, Finlândia, Alemanha, Islândia, Letônia, Lituânia, Noruega, Polônia, Rússia e Suécia. A finalidade da reunião era examinar os resultados conseguidos pela rede de ministros, no cumprimento das tarefas dadas na primeira reunião ministerial no palácio de Haga em março de 2000, e adotar a Agenda 21 na educação para o desenvolvimento sustentável da região do Mar Báltico. As principais definições foram no sentido de incentivar a cooperação internacional a respeito das pesquisas envolvendo a temática ambiental, criar um suporte para as redes que compartilham das experiências e atividades comuns em todos os níveis. O projeto do Mar Báltico pode, conseqüentemente, ser visto como um ator importante na disseminação de boas práticas para o desenvolvimento sustentável (HAGA DECLARATION, 2000, 2002).

\subsection{Panorama atual da situação das IES quanto à gestão ambiental}

Segundo Delgado e Vélez (2005), existem atualmente cerca de 140 IES que incorporaram políticas ambientais na administração e na gestão acadêmica. Dentro dessas IES que adotaram compromissos e políticas ambientais para o desenvolvimento sustentável, dez IES estão certificadas com ISO 14001, como é o caso da Universidade da Organização das Nações Unidas em Tókio no Japão.

Ribeiro et al. (2005) mencionam que a IES considerada pioneira na implantação de um SGA é a Universidade Mälardalen, na Suécia. Atualmente, esta universidade está certificada segundo a norma ISO 14001.

Ainda nesta perspectiva, existe na Europa o projeto Ecocampus, que é um sistema de gerenciamento ambiental direcionado as IES. O projeto permite o reconhecimento das faculdades e universidades a serem reconheci- das por suas práticas de sustentabilidade ambiental. Estão abertas a todas as instituições engajadas nos programas de melhoria contínua na área ambiental.

O Ecocampus foi projetado de forma flexível, permitindo um atendimento gradativo na sua execução, destacando alguns exemplos chave da sustentabilidade (Blewitt, 2001):

- Contribui para o desenvolvimento da ética sustentável;

- Controla os transportes dentro do campus;

- Prima pelo bem estar, saúde e segurança;

- Reduz os desperdícios;

- Aprimora as atividades ambientais curriculares;

- Monitora o consumo de água e energia; e

- Motiva a participação da comunidade local e regional.

O projeto é baseado visando o estabelecimento de um sistema de gerência ambiental compatível com a ISO 14001. Os certificados das realizações são concedidos às instituições por um corpo independente de certificação, em todos os estágios, durante todo o projeto do Ecocampus, servindo como motivação para a progressão e desempenho na implantação.

Atualmente, observa-se que o Reino Unido lidera o movimento universitário para o desenvolvimento sustentável na Europa e constata-se a existência de uma estrutura de ligação de âmbito nacional, a Environmental Association for Universities and Colleges (EAUC), que serve de interlocutora das universidades britânicas junto às estruturas nacionais, regionais e internacionais.

\section{Metodologia}

Os resultados apresentados neste artigo referentes às práticas ambientais desenvolvidas pelas universidades foram obtidos por meio de uma extensa revisão bibliográfica sobre o tema em IES localizadas no Brasil e em outros países. A partir dos resultados encontrados, foi elaborada uma lista de ações sustentáveis contemplando todas as iniciativas adotadas pelas universidades pesquisadas.

Foram pesquisadas 42 universidades localizadas no Reino Unido, Estados Unidos, Canadá, Portugal, Alemanha, Espanha, França e Nova Zelândia. No Brasil apresenta-se o caso de 4 universidades.

O modelo proposto para a gestão ambiental em uma Instituição de Ensino Superior baseou-se nas boas práticas encontradas e sua estruturação foi concebida a partir das normas para sistemas de gestão ambiental, NBR ISO 14001 e NBR ISO 14004 (ABNT, 1997a; 1997b), além do ciclo PDCA.

O ciclo PDCA pode ser brevemente descrito:

- Planejar (PLAN): envolve o estabelecimento dos objetivos e processos necessários para atingir os resultados, de acordo com a política ambiental da organização; 
- Executar $(D O)$ : envolve a implementação dos processos;

- Verificar (CHECK): envolve o monitoramento e medição dos processos em conformidade com a política ambiental, objetivos, metas, requisitos legais e outros, e relatar os resultados; e

- Agir $(A C T I O N)$ : envolve a execução de ações para melhorar continuamente o desempenho do sistema da gestão ambiental.

Este modelo está em fase de implantação na Faculdade de Horizontina (FAHOR), localizada na cidade de Horizontina, noroeste do RS. No entanto, os resultados de sua aplicação não são foco deste artigo.

\section{Apresentação dos resultados}

\subsection{Iniciativas e boas práticas de sustenta- bilidade das universidades}

No processo de pesquisa, foi possível encontrar diversos casos de gestão ambiental em âmbito universitário. Dois aspectos devem ser ressaltados em relação aos resultados: as ações são isoladas e pontuais; e a maioria destina-se a situações em que a instituição já está implementada e funcionando, facilitando as ações de formação do pessoal, a distribuição de responsabilidades do programa de gestão ambiental e o monitoramento e controle dos indicadores de gestão para o SGA.

As Tabelas de 1 a 3 apresentam, de forma resumida, as ações sustentáveis encontradas nas universidades pesquisadas. Os casos estão organizados de acordo com a localização das instituições. As linhas hachuradas indicam que a iniciativa é adotada pela IES.

A Tabela 1 apresenta um resumo das universidades com ações sustentáveis localizadas no Reino Unido (Blewitt, 2001)

A Tabela 2 apresenta um resumo das universidades com ações sustentáveis localizadas em Portugal, Alemanha, Espanha, França, Nova Zelândia e América Latina (Bonnet et al., 2002, Fouto (2002); Careto e Vendeirnho, 2003; Pontifica Universidad Javeriana, 2003; Ribeiro et al. 2005; Delgado e Vélez, 2005).

A Tabela 3 apresenta um resumo das universidades com ações sustentáveis localizadas nos Estados Unidos e Canadá (Careto e Vendeirinho, 2003)

Do total das 42 IES pesquisadas, as ações sustentáveis que mais aparecem são o controle do consumo e reuso da água e o programa de reciclagem-gestão de resíduos, em torno de $22 \%$ dos casos, seguidos do treinamento e sensibilização dos alunos, com $19 \%$ dos casos. Outros dois aspectos que aparecem em $16 \%$ das IES foram a auditoria ambiental para indicar melhorias onde necessário e do Diagnóstico dos impactos diretos ou significativos para o ambiente.
Sob o ponto de vista das IES, o número maior de ações sustentáveis foi encontrado na Cornwall College (REINO UNIDO) e na Louisville Universidade (EUA) correspondendo a 8 iniciativas (18\% do total).

A Figura 4 relaciona as iniciativas adotadas pelas universidades pesquisadas de acordo com as etapas de implantação de um sistema de gestão ambiental, o ciclo PDCA.

\subsubsection{Casos de IES localizadas no Brasil}

O exemplo brasileiro mais importante de universidade que implementou um Sistema de Gestão Ambiental é a Universidade do Vale do Rio dos Sinos (UNISINOS). Por intermédio do projeto Verde Campus, a UNISINOS foi a primeira universidade da América Latina a ser certificada segundo a ISO 14001. O projeto visa à preservação, à melhoria e à recuperação da qualidade ambiental, assegurando condições de desenvolvimento socioeconômico, segurança do trabalho, proteção da vida e qualidade ambiental. Um dos resultados mais relevantes alcançados foi a criação do curso de Gestão Ambiental no ano de 2005. Com isso, a UNISINOS possibilitou a criação de laboratórios para estudos ambientais, pesquisas básicas e aplicadas e, ainda, ferramentas de geoprocessamento e demais recursos técnicos e humanos necessários para a formação de seus alunos (VERDE CAMPUS, 1997).

A Universidade Federal de Santa Catarina (UFSC) é um exemplo de tentativa da implementação de um SGA. Foi criada uma coordenadoria de Gestão Ambiental, ligada diretamente ao gabinete da reitoria, e, ainda, foi estabelecida uma política de gestão ambiental responsável. Por meio desta, privilegiou-se utilizar o ensino como uma busca contínua para melhorar a relação homem e meio ambiente, trazendo a comunidade como parceira dessa proposta e visando uma melhor qualidade de vida pela geração do conhecimento (Ribeiro et al. 2005).

$\mathrm{Na}$ prática, alguns programas propostos já estão em andamento. No sistema de coleta dos resíduos químicos da UFSC, por exemplo, uma empresa terceirizada é a responsável pela coleta e destinação final adequada destes resíduos. Ainda foi desenvolvido, por meio de parceria com órgãos públicos estaduais, ONGs e associações, o Projeto Sala Verde. Esta atividade consiste em criar um espaço na instituição dedicado ao delineamento e desenvolvimento de atividades de caráter educacional, tendo como uma das principais ferramentas a divulgação e a difusão de publicações sobre Meio Ambiente (Ribeiro et al. 2005).

Também no Estado de Santa Catarina aparece a Universidade Regional de Blumenau (FURB). "A FURB é uma instituição comprometida com a proteção ambiental e com a economia dos recursos naturais, visando uma melhoria na qualidade de vida atual e futura (Política Ambiental da FURB)". A Instituição efetivou a sua postura ambien- 
Tabela 1. Iniciativas e boas práticas de universidades no Reino Unido.

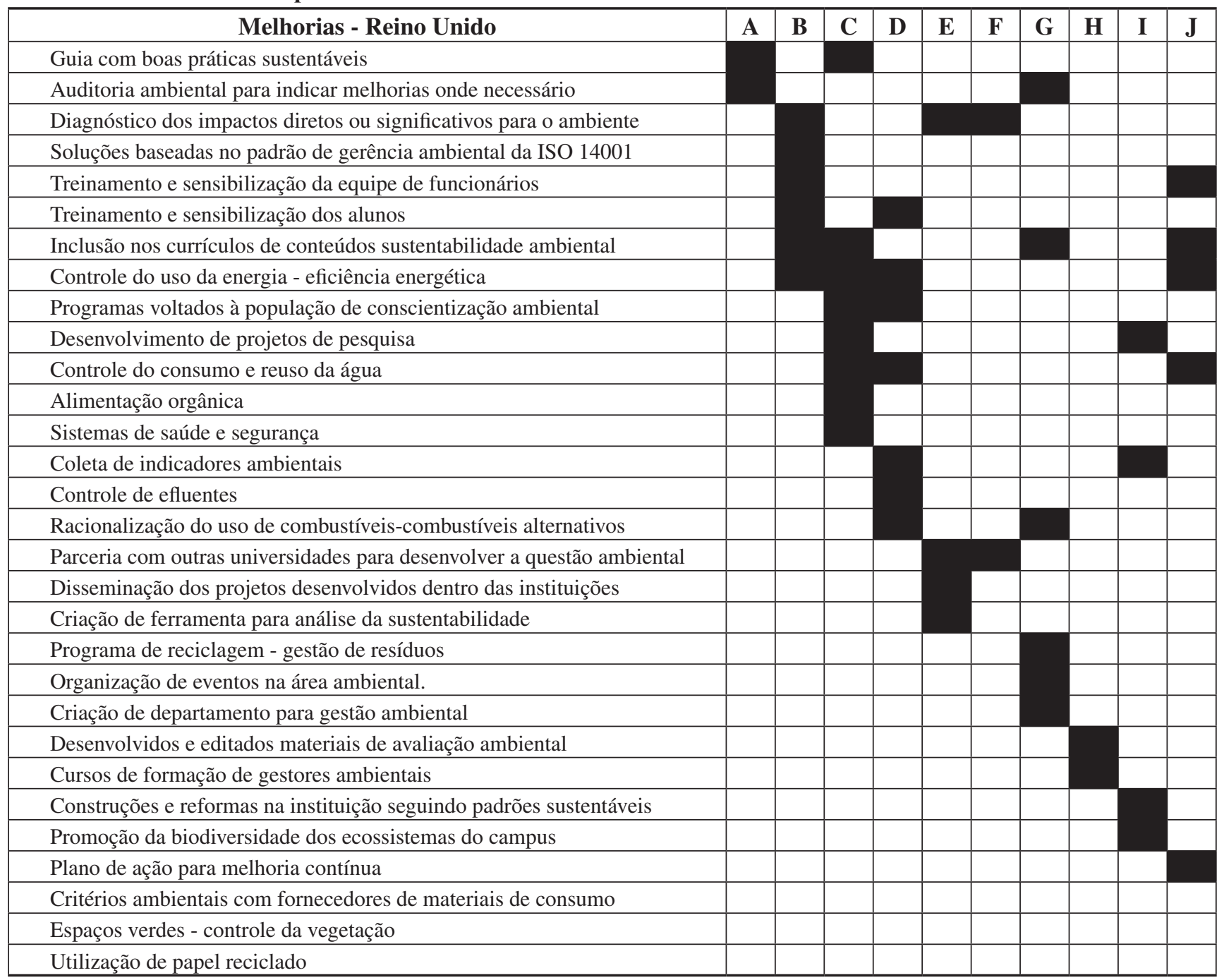

A - Bishop Burton College; B - Blackburn College; C - Cornwall College; D - Huddersfield New College; E - Southgate College, Enfield College e Capel Manor Horticultural College \& Environmental Centre; F - South West Association for Education and Training (SWAFET); G - St Helens College; H - Walford e North Shropshire College; I - Walsall College of Arts and Technology; e J - Wigan e Leigh College Wigan.

talmente consciente criando o Comitê de Implantação do SGA em março de 1998, constituído por representantes de toda a comunidade universitária, objetivando identificar com clareza os seus problemas ambientais, a fim de estabelecer um plano de melhoria contínua na atenuação ou eliminação desses problemas. Este Comitê, seguindo as normas da ISO 14001, elaborou a Política Ambiental da FURB e deu início ao Planejamento Ambiental, culminando com a criação do Sistema de Gestão Ambiental da Universidade em 1999. O Sistema de Gestão Ambiental da FURB é uma estrutura organizacional e de responsabilidades destinada a implementar a política ambiental e os objetivos de gestão ambiental da FURB e é composto pela Coordenadoria do Meio Ambiente, Responsáveis e Agentes Ambientais (Butzke, Pereira e Noebauer, 2002).
Conforme Ribeiro et al. (2005), a Universidade Federal do Rio Grande do Sul (UFRGS) também vem se empenhando em implementar um SGA. Inicialmente foi realizado um diagnóstico sobre os resíduos gerados e suas diferentes destinações nas unidades da universidade. Com esta iniciativa, foi possível obter informações muito úteis acerca dos resíduos gerados pela UFRGS. Analisando o diagnóstico realizado a partir dos dados obtidos na UFRGS, foi constatada a existência de algumas iniciativas pontuais objetivando melhoras nos aspectos ambientais da universidade. Na Escola de Engenharia, um grupo formado por estudantes do curso de Engenharia de Materiais planejou um sistema de Gerenciamento de Resíduos Sólidos Urbanos (GRSU). Com o apoio da unidade, este grupo implementou o GRSU em 2004. Embora o projeto 
Tabela 2. Iniciativas e boas práticas de universidades na Europa e América Latina.

\begin{tabular}{|c|c|c|c|c|c|c|c|c|c|c|c|c|c|c|c|}
\hline Melhorias - Portugal, Alemanha, Espanha, França e Nova Zelândia & $\mathbf{A}$ & $\mathbf{B}$ & $\mathbf{C}$ & $\mathbf{D}$ & $\mathbf{E}$ & $\mathbf{F}$ & $\mathbf{G}$ & $\mathbf{H}$ & $\mathbf{I}$ & $\mathbf{J}$ & \begin{tabular}{l|l}
$\mathbf{L}$ & $\mathbf{I}$ \\
\end{tabular} & $\mathbf{M}$ & $\mathbf{N}$ & $\mathbf{O}$ & $\mathbf{P}$ \\
\hline Guia com boas práticas sustentáveis & & & & & & & & & & & & & & & \\
\hline Auditoria ambiental para indicar melhorias onde necessário & & & & & & & & & & & & & & & \\
\hline Diagnóstico dos impactos diretos ou significativos para o ambiente & & & & & & & & & & & & & & & \\
\hline Soluções baseadas no padrão de gerência ambiental da ISO 14001 & & & & & & & & & & & & & & & \\
\hline Treinamento e sensibilização da equipe de funcionários & & & & & & & & & & & & & & & \\
\hline Treinamento e sensibilização dos alunos & & & & & & & & & & & & & & & \\
\hline Inclusão nos currículos de conteúdos sustentabilidade ambiental & & & & & & & & & & & & & & & \\
\hline Controle do uso da energia - eficiência energética & & & & & & & & & & & & & & & \\
\hline Programas voltados a população de conscientização ambiental & & & & & & & & & & & & & & & \\
\hline Desenvolvimento de projetos de pesquisa & & & & & & & & & & & & & & & \\
\hline Controle do consumo e reuso da água & & & & & & & & & & & & & & & \\
\hline Alimentação orgânica & & & & & & & & & & & & & & & \\
\hline Sistemas de saúde e a segurança & & & & & & & & & & & & & & & \\
\hline Coleta de indicadores ambientais & & & & & & & & & & & & & & & \\
\hline Controle de efluentes & & & & & & & & & & & & & & & \\
\hline Racionalização do uso de combustíveis-combustíveis alternativos & & & & & & & & & & & & & & & \\
\hline Parceria com outras universidades & & & & & & & & & & & & & & & \\
\hline Disseminação dos projetos desenvolvidos dentro das instituições & & & & & & & & & & & & & & & \\
\hline Criação de ferramenta para análise da sustentabilidade & & & & & & & & & & & & & & & \\
\hline Programa de reciclagem - gestão de resíduos & & & & & & & & & & & & & & & \\
\hline Organização de eventos na área ambiental. & & & & & & & & & & & & & & & \\
\hline Criação de departamento para gestão ambiental & & & & & & & & & & & & & & & \\
\hline Desenvolvidos e editados materiais de avaliação ambiental & & & & & & & & & & & & & & & \\
\hline Cursos de formação de gestores ambientais & & & & & & & & & & & & & & & \\
\hline Construções e reformas na instituição seguindo padrões sustentáveis & & & & & & & & & & & & & & & \\
\hline Promoção da biodiversidade dos ecossistemas do campus & & & & & & & & & & & & & & & \\
\hline Plano de ação para melhoria contínua & & & & & & & & & & & & & & & \\
\hline Critérios ambientais com fornecedores de materiais de consumo & & & & & & & & & & & & & & & \\
\hline Espaços verdes - controle da vegetação & & & & & & & & & & & & & & & \\
\hline Utilização de papel reciclado & & & & & & & & & & & & & & & \\
\hline
\end{tabular}

A - Universidade do Algarve (Portugal); B - Universidade de Aveiro (Portugal); C - Universidade Técnica de Lisboa (Portugal); D - Universidade de Nova Lisboa (Portugal); E - Universidade de Zittau Görlitz, (Alemanha); F - Universidade Autônoma de Barcelona (Espanha); G - Universidade Autônoma de Madrid (Espanha); H - Universidade de Granada (Espanha); I - Universidade de Bordeaux (França); J - Universidade de Auckland (Nova Zelândia); L - Universidade Nacional Autônoma do México (México); M - Pontifícia Universidad Javeriana (Colômbia); N - Universidad Externado de Colômbia (Colômbia); 0 - Universidad Nacional de Colômbia (Colômbia); e P - Universidad Del Valle (Colômbia).

tenha atingido seus objetivos nos primeiros meses de implementação, o afastamento gradual dos estudantes que o iniciaram, associado à falta de envolvimento da alta administração, foram fatores que causaram a desestruturação do projeto. A Escola de Administração é outra unidade da UFRGS que também vem desenvolvendo atividades relacionadas à Gestão Ambiental. A partir da iniciativa de um grupo de alunos orientados por um professor, também foi proposta a implementação de um Sistema de Gerenciamento de Resíduos Sólidos Urbanos nesta unidade. O grupo realizou o levantamento dos resíduos gerados e, atualmente, ações possíveis para a diminuição do consumo de energia e água estão em implantação.

Conforme a iniciativa das instituições apresentadas acima, nota-se a predominância de projetos abordando o gerenciamento de resíduos. Esse gerenciamento é uma importante etapa no futuro desenvolvimento do Sistema de Gestão Ambiental.

Na visão de Ribeiro et al. (2005), ao proceder à análise dessas iniciativas na UFRGS, ainda existem barreiras na implementação do SGA, entre elas: a falta de informação da sociedade sobre práticas sustentáveis; a não valorização do meio ambiente por diversos colaboradores da organização; e a não percepção da universidade como uma fonte potencial de poluição.

\subsection{Proposta de modelo de gestão ambiental para IES}

As universidades anteriormente mencionadas, assim como um número crescente de empresas que desenvol- 
Tabela 3. Iniciativas e boas práticas de universidades nos Estados Unidos e Canadá.

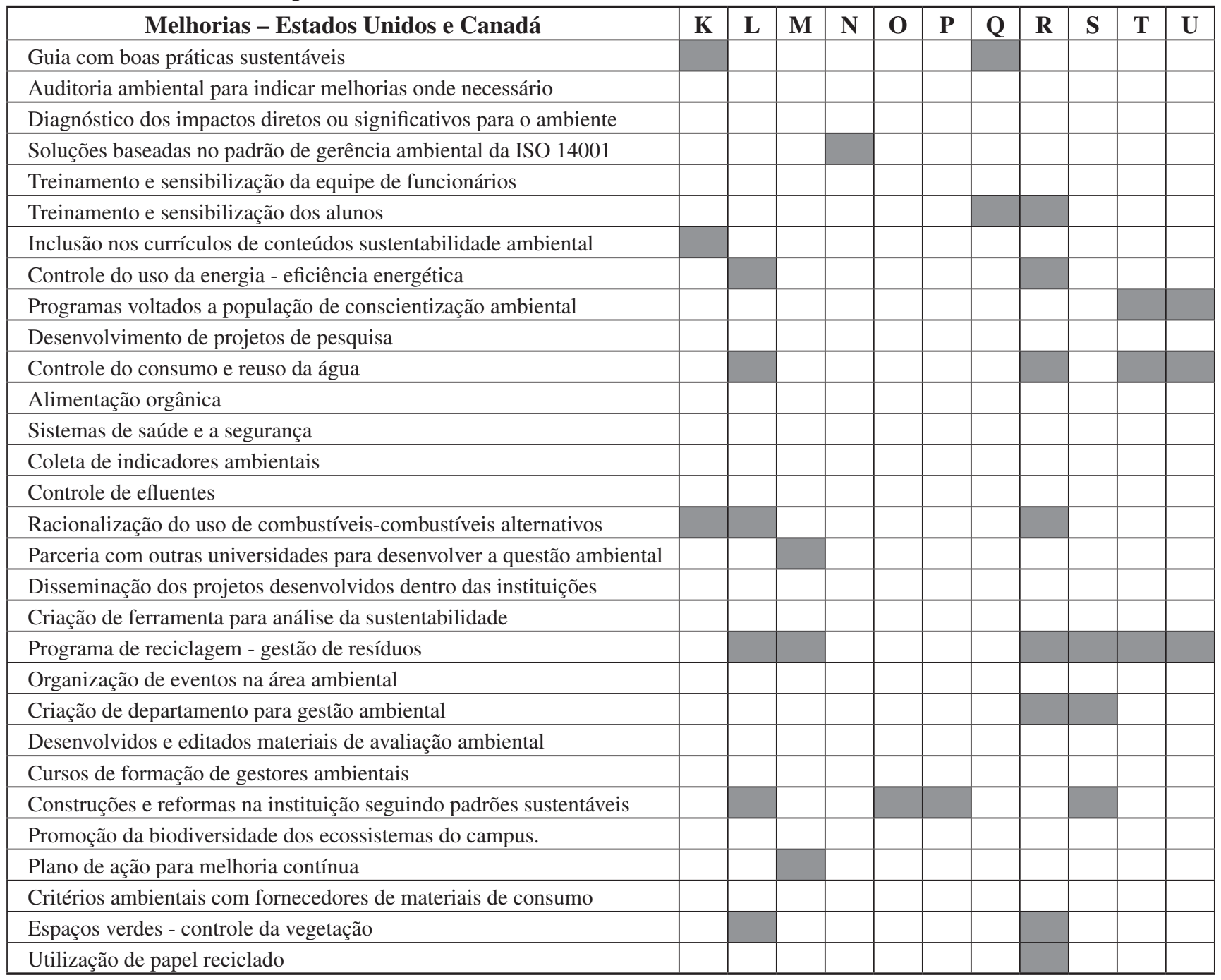

K - Vermont University (EUA); L - Burlington University (EUA); M - Michigan University (EUA); N - University of South Carolina (EUA); O - University of Missouri-Roll (EUA); P - Emory University (EUA); Q - Carnegie Mellon University (EUA); R - Louisville Universidade (EUA); S - Middlebury College (EUA); T -British University (Canadá); e U - Harvard University (EUA).

vem um SGA em sua organização, devem ter sua concepção, para a busca da certificação, segundo a norma ISO 14001. Algumas etapas somente podem ser concebidas conforme um programa que oriente a melhoria do desempenho ambiental da organização, prevendo os seguintes passos: política ambiental; planejamento; implementação e operacionalização; verificação e ação corretiva; e uma revisão permanente (PDCA).

A Figura 5 apresenta uma proposta de procedimentos para implantar um modelo de gestão ambiental e demonstra, de forma sucinta, as principais etapas desse processo. A concepção está baseada no ciclo PDCA.

O levantamento dos requisitos legais e aspectos ambientais deverá influenciar a definição da Política Ambiental de um campus. Depois de identificados os aspectos ambientais, pode ser aplicado o ciclo do PDCA. Com a identificação dos aspectos ambientais da atividade exercida pela IES e a criação da política ambiental, podese avaliar e determinar quem será responsável por cada etapa do processo, quais as mudanças físicas necessárias e, principalmente, qual a receita disponível para investir nesse projeto de melhoria. Após a execução do proposto, segue-se com o monitoramento das etapas produtivas, buscando corrigir falhas que possam existir e minimizar possíveis problemas que não condizem com o objetivo do SGA.

Como etapa final desse ciclo, faz-se necessária uma análise crítica sobre o que foi melhorado, se a política ambiental foi seguida e se o SGA conseguiu atingir seus objetivos. Por ser um ciclo, o SGA, a partir daí, volta a aplicar sua política, buscar possíveis novos aspectos ambientais que passam a ser observados após a execução do PDCA. Avaliar novamente os recursos disponíveis para melhorar o processo, seguir o monitoramento das ações e 


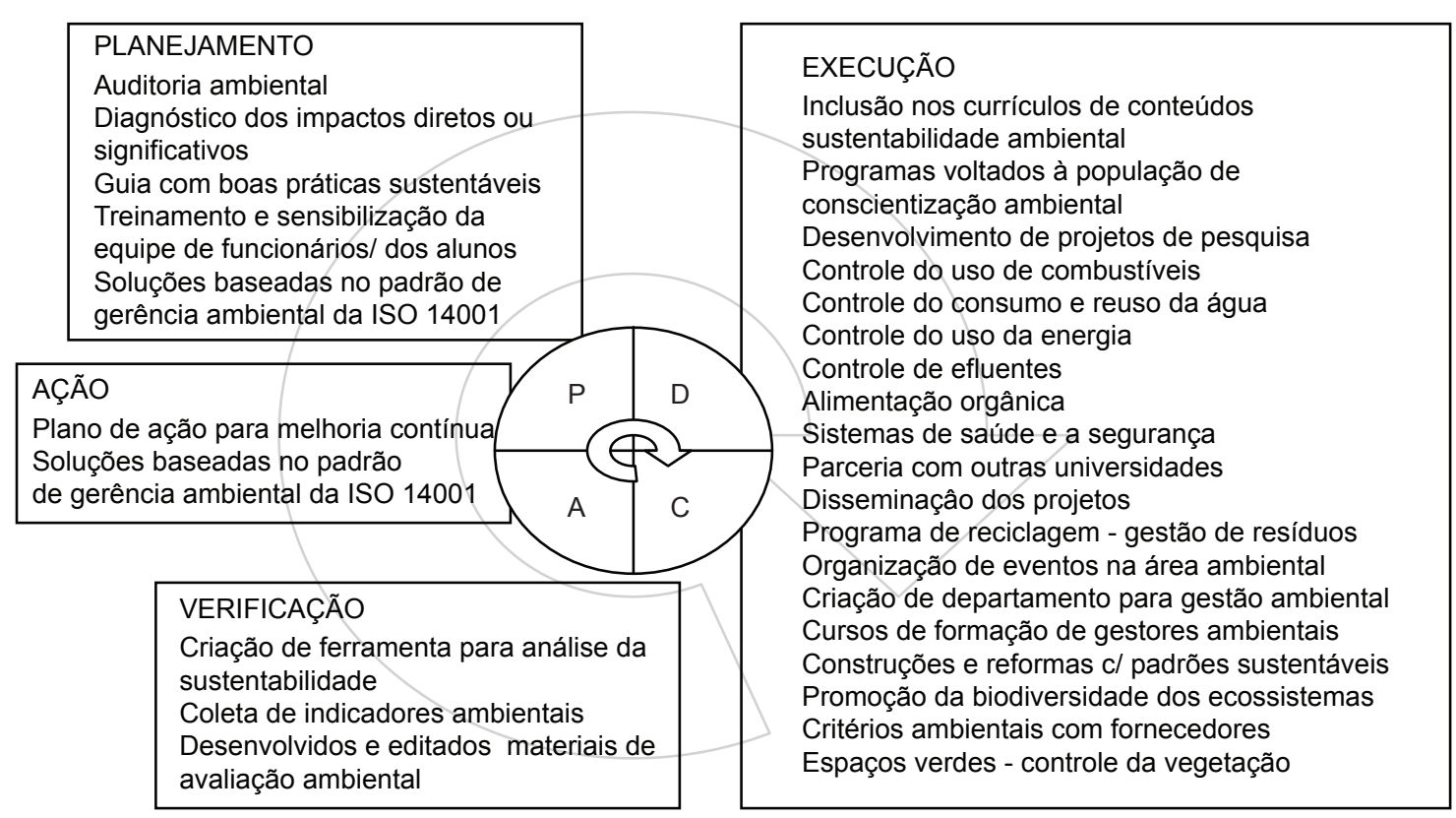

Figura 4. Iniciativas e boas práticas de universidades de acordo com o PDCA.
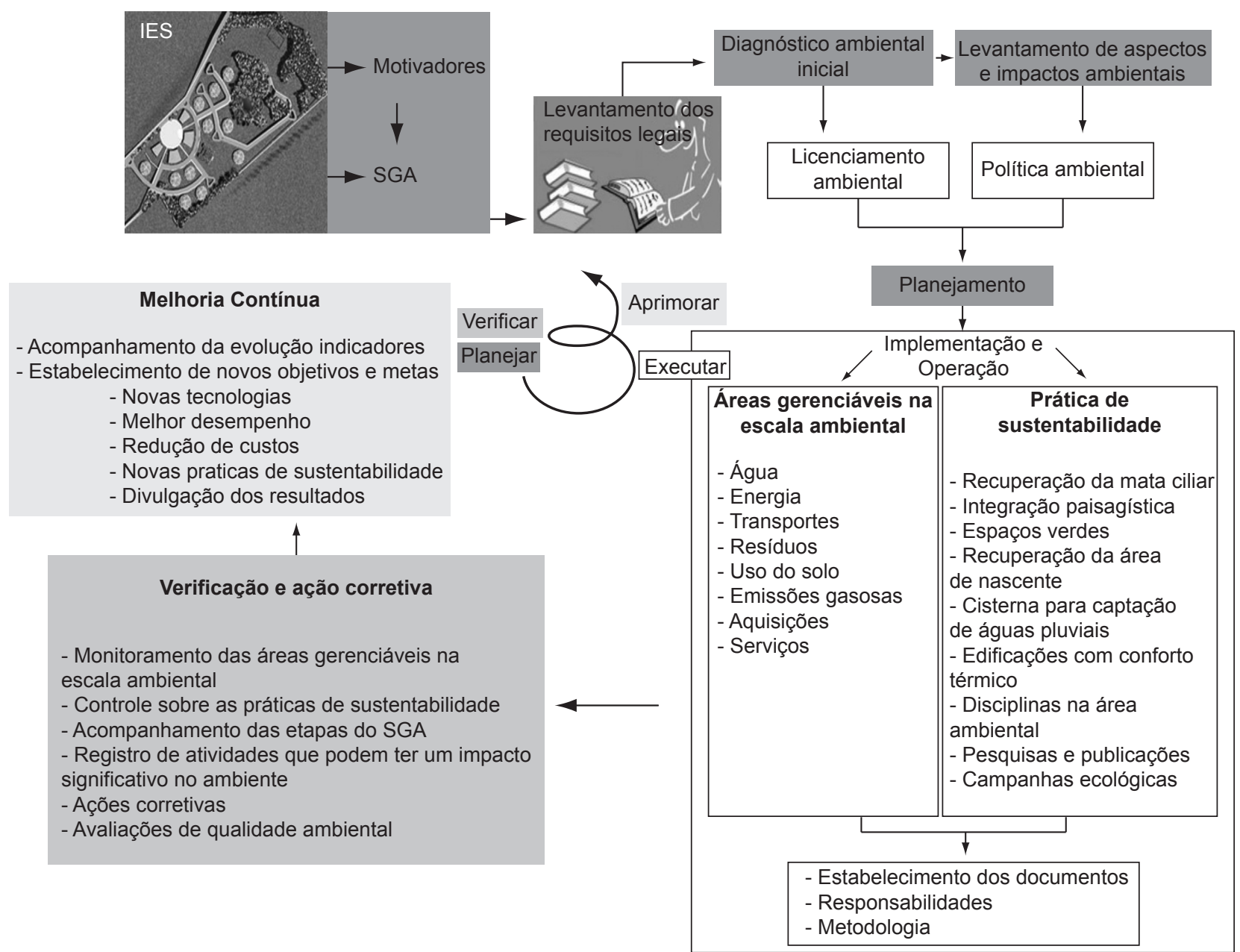

Figura 5. Modelo de gestão ambiental para IES. 
realizar novas análises, sempre com o objetivo principal do ciclo que é a melhoria contínua do SGA.

A gestão ambiental em universidades deve: incluir análises responsáveis e detalhadas de cada fluxo num campus, devendo ser baseada em unidades físicas, porém permitindo também que sejam considerados questões econômicas; incluir a avaliação de indicadores consistentes; envolver o estudo detalhado destes indicadores a fim de compreender e estimar o potencial de melhoria do sistema; e servir de melhoria contínua dos parâmetros ambientais do sistema, de acordo com o comprometimento ambiental exemplar que as instituições precisam demonstrar.

\section{Considerações finais}

Com a apresentação de um modelo de atuação para as universidades em matéria de desenvolvimento sustentável, espera-se ter conseguido justificar, à escala global, que existem motivos claros para investimentos das IES neste sentido. Esses motivos substanciam desde diretrizes a modelos ou guias de atuação e práticas de sustentabilidade para implantação de um SGA nas IES.

Os casos de gestão ambiental em âmbito universitário encontrados no mundo e no Brasil constituem, na maioria das vezes, práticas isoladas em situações em que a instituição já está implementada e funcionando. Esta situação revela a preocupação crescente de adaptação das universidades em busca de um desenvolvimento susten- tável, não só no aspecto do ensino, mas de práticas de funcionamento ambientalmente corretas.

As ações que aparecem incorporadas a um SGA para as IES podem ser resumidas:

Assessoria ambiental, trabalhos de levantamento de aspectos e impactos ambientais e elaboração do SGA; Gestão de recursos - gestão de energia, gestão da água, qualidade e conforto térmico; Gestão de resíduos, prevenção da poluição; Construção sustentável - plano diretor definido para todos os prédios a serem construídos; Compras integrando critérios ambientais - materiais e equipamentos; Educação integrando aspectos ambientais - sensibilização ambiental, formação, informação, currículo integrando aspectos ambientais, projetos de investigação sobre temas do SGA, campanhas; Declarações e relatórios ambientais - para uma fase posterior ao SGA e após a sua revisão; Investimentos nos aspectos paisagísticos, recuperação da mata ciliar, criação da biblioteca natural, espaços verdes; e Sistema de captação de águas pluviais e utilização nas bacias sanitárias, mictórios e jardins.

Finalmente, é importante salientar que os benefícios de um SGA são muitos e, entre eles, destacam-se as economias pelo melhoramento da produtividade e da redução no consumo de energia, água e materiais de expediente; o estabelecimento das conformidades com a legislação ambiental; reduzindo, assim, os riscos de incorrer em penalidades ou gerar passivos ambientais; a evidência de práticas responsáveis e melhora na imagem externa da instituição; e a geração de oportunidades de pesquisa.

\section{Referências Bibliográficas}

AGENDA 21 (1992). Disponível em: www.crescentefertil. org.br/agenda21/index2.htm. Acesso em: 20 jul. 2005.

ASSOCIAÇÃO BRASILEIRA DE NORMAS TÉCNICAS. NBR ISO 14001. Sistemas de Gestão Ambiental - Especificação e diretrizes para uso. Rio de Janeiro. ABNT, 1997a.

ASSOCIAÇÃO BRASILEIRA DE NORMAS TÉCNICAS. NBR ISO 14004. Sistemas de Gestão Ambiental - Diretrizes gerais sobre princípios, sistemas e técnicas de apoio. Rio de Janeiro. ABNT, 1997b.

BLEWITT, J. Good Practice in SustainableDevelopment Education: Evaluation Report and Good Practice Guide. 2001. Disponível em: http://www.lsda.org.uk/research/sustainability/goodpractice.pdf Acesso em:15 mai 2005.

BONNET, J. F. et al. Analysis of electricity and water enduses in university campuses: case-study of the University of Bordeaux in the framework of the Ecocampus European Collaboration. Journal of Cleaner Production, 2002. Disponível em: http://www.sciencedirect.com Acesso em: 06 dez. 2005.

BUTZKE, I. C.; PEREIRA G. R.; NOEBAUER D. Sugestão de Indicadores para Avaliação do Desempenho das Atividades Educativas do Sistema de Gestão Ambiental - SGA da Universidade Regional de Blumenau. 2002.

Revista Eletrônica do Mestrado em Educação Ambiental. Vol 13.Disponível em: http://www.fisica.furg.br/ mea/remea/congress/artigos/comunicacao13.pdf. Acesso em: 05 mai 2006.

CARETO, H.; VENDEIRINHO, R. Sistemas de Gestão Ambiental em Universidades: Caso do Instituto Superior Técnico de Portugal. Relatório Final de Curso, 2003. Disponível em: http://meteo.ist.utl.pt/ jjdd/LEAMB/LEAmb\%20TFC\%20site\%20v1/2002-2003/HCa- 
reto_RVendeirinho\%20artigo.pdf Acesso em: 10 mai. 2005.

COPERNICUS - THE UNIVERSITY CHARTER FOR SUSTAINABLE DEVELOPMENT, 1994 - Disponível em: http://www.iisd.org/educate/declarat/coper.htm. Acesso em: 28 nov. 2005.

DELGADO, C. C. J.; VÉLEZ, C. Q. Sistema de Gestión Ambiental Universitária: Caso Politécnico Gran Colombiano.2005. Disponível em: http://ecnam.udistrital. edu.co/pdf/r/edge02/node03.pdf. Acesso em: 09 dez. 2005.

ECOCAMPUS (1997) Universidad Autónoma de Madrid. Disponível em: www.uam.es/servicios/ecocampus/especifica/proyecto.html. Acesso em: 12 jun. 2005.

FOUTO, A. R. F. O papel das universidades rumo ao desenvolvimento sustentável: das relações internacionais às práticas locais. Dissertação. (Mestrado em Gestão e Políticas Ambientais Relações Internacionais do Ambiente), 2002. Disponível em: http://campus.fct. unl.pt/campusverde/W_RIA_ARFF.doc Acesso em: 08 dez. 2005.

INTERNATIONAL ASSOCIATION OF UNIVERSITIES. Educations for Sustainable Development. 1993. Disponível em: http://portal.unesco.org/education. Acesso em: 20 nov. 2005.

KRAEMER, MARIA E. P. Gestão Ambiental: Um Enfoque no Desenvolvimento Sustentável, 2004. Disponível em http://www.gestaoambiental.com.br/kraemer.php. Acesso em 28 de novembro de 2005

MAYOR, F. Preparar um futuro viável: ensino superior e desenvolvimento sustentável. In: Conferência mundial sobre o ensino superior. Tendências de educação superior para o século XXI. Anais. Paris: 1998.

OIUDSMA. ASOCIACIÓN INTERNACIONAL DE UNIVERSIDADES POR EL DESARROLLOSOSTENIBLE Y EL MEDIO AMBIENTE. 2002. Disponível em: http:// www.ugr.es/ oiudsma/Welcome.htm Acesso em: 10 abr. 2005.
PONTIFICA UNIVERSIDAD JAVERIANA. Sistema de Gestión ambiental. 2003. Disponivel em: http://www. javeriana.edu.co/ Facultades/fear/institutos/inicio.htm. Acesso em: 08 Ago. 2005

RIBEIRO, A. L. et al. Avaliação de barreiras para implementação de um sistema de gestão ambiental na UFRGS. In: XXV Encontro Nacional de Engenharia de Produção, Porto Alegre, RS, 2005.

TAUCHEN et al. Gestão Ambiental: Um modelo da Faculdade Horizontina. In: XII SIMPEP. Bauru, SP. Disponível em: http://simpep.feb.unesp.br. Acesso em: 02 dez. 2005.

THE HAGA DECLARATION (2000, 2002). Disponível em: http://pub.uvm.dk/2003/learnersguide/html/chapter02.htm. Acesso em: 25 nov. 2005.

THE HALIFAX DECLARATION, 1991. Disponível em: http://www.iisd.org/educate/declarat/halifax.htm. Acesso em 28 nov. 2005.

THE KYOTO DECLARATION, 1993. Disponível em: http://www.iisd.org/educate/declarat/kyoto.htm. Acesso em 28 nov. 2005.

THE SWANSEA DECLARATION, 1993. Disponível em: http://www.iisd.org/educate/declarat/swansea.htm. Acesso em 28 nov. 2005.

THE TALLOIRES DECLARATION, 1990. Disponível em: http://ulsf.org/programs_talloires.html. Acesso em: 20 julho 2005.

VERDE CAMPUS (1997). UNISINOS. Disponível em: http://www.unisinos.br/verdecampus/. Acesso em: 12 dez. 2005.

ZITZKE, V. A. Educação Ambiental e Ecodesenvolvimento. Revista Eletrônica do Mestrado em Educação Ambiental. v. 9, 2002. Disponível em: http://www.fisica.furg.br/mea/remea/vol9/a13art16.pdf. Acesso em: 28 nov. 2005. 


\title{
ENVIRONMENTAL MANAGEMENT IN HIGHER-EDUCATION INSTITUTIONS: A MODEL FOR IMPLEMENTATION AT A UNIVERSITY CAMPI
}

\begin{abstract}
In the last few years, sustainable development and environmental management have become one of the main interests of higher-education institutions. This has been revealed mainly by the educational approach on environmental management and the practical examples incorporated in campi operation. The present work shows a systematization of procedures and a model whose purpose it is to implement an adapted environmental management system (EMS) at a university campus, making it possible for a higher-education institution to control and prevent environmental impacts and adjust to legislation and regulations, even in the infrastructure planning phase. The proposal is based on PDCA tools and on a comprehensive survey of national and international benchmarks for sustainable university campi. The examples presented indicate isolated actions in the surveyed universities, most of them implemented when the campus is already functioning. This situation shows a growing concern regarding the adaptation of universities in search of sustainable development, not only regarding educational aspects, but also regarding environmentally correct practices.
\end{abstract}

Keywords: university, campi, environmental management, sustainable development. 
